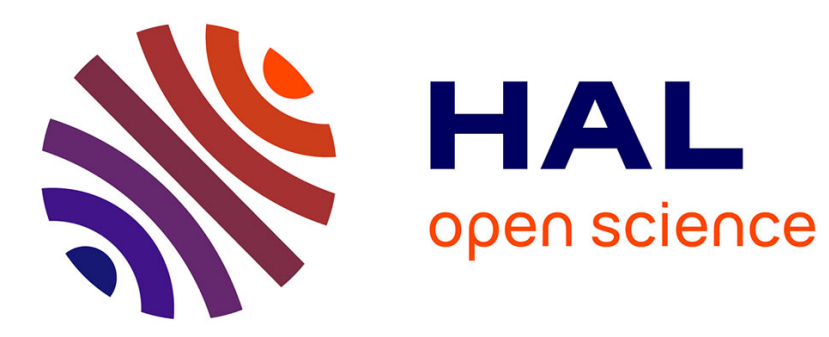

\title{
Antiferromagnetic coupling in copper(II)porphyrin dimers linked by copper(II) or palladium(II) ion
}

Mary-Ambre Carvalho, Hervé Dekkiche, Sébastien Richeter, Corinne Bailly,

Lydia Karmazin, Declan Mckearney, Daniel Leznoff, Guillaume Rogez, Bertrand Vileno, Sylvie Choua, et al.

\section{To cite this version:}

Mary-Ambre Carvalho, Hervé Dekkiche, Sébastien Richeter, Corinne Bailly, Lydia Karmazin, et al.. Antiferromagnetic coupling in copper(II)porphyrin dimers linked by copper(II) or palladium(II) ion. Journal of Porphyrins and Phthalocyanines, 2020, 24 (01n03), pp.238-246. 10.1142/S1088424619501037. hal-02391346

\section{HAL Id: hal-02391346 \\ https://hal.science/hal-02391346}

Submitted on 6 Nov 2020

HAL is a multi-disciplinary open access archive for the deposit and dissemination of scientific research documents, whether they are published or not. The documents may come from teaching and research institutions in France or abroad, or from public or private research centers.
L'archive ouverte pluridisciplinaire HAL, est destinée au dépôt et à la diffusion de documents scientifiques de niveau recherche, publiés ou non, émanant des établissements d'enseignement et de recherche français ou étrangers, des laboratoires publics ou privés. 


\title{
Antiferromagnetic coupling in copper(II)porphyrin dimers linked by copper(II) or palladium(II) ion
}

\author{
Mary-Ambre Carvalho ${ }^{a}$, Hervé Dekkiche ${ }^{\mathrm{a}}$, Sébastien Richeter ${ }^{\mathrm{b}}$, Corinne Bailly ${ }^{\mathrm{a}}$, Lydia \\ Karmazin $^{\mathrm{a}}$, Declan McKearney ${ }^{\mathrm{c}}$, Daniel B. Leznoff ${ }^{c}$, Guillaume Rogez ${ }^{\mathrm{d}}$, Bertrand \\ Vileno $^{\mathrm{a}}$, Sylvie Choua ${ }^{\mathrm{a} *}$, Romain Ruppert ${ }^{\mathrm{a} *}$
}

Dedicated to Professor Atsuhiro Osuka on the occasion of his 65th birthday.

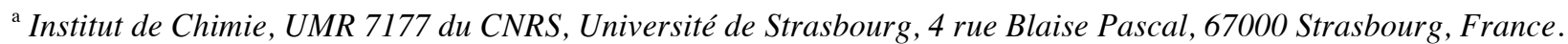

${ }^{\mathrm{b}}$ Institut Charles Gerhardt, UMR5253 CNRS-ENSCM-UM, Place Eugène Bataillon, CC1701, 34095 Montpellier, France

${ }^{\mathrm{c}}$ Department of Chemistry, Simon Fraser University, Burnaby, British Columbia V5A 1S6, Canada.

${ }^{\mathrm{d}}$ Institut de Physique et de Chimie des Matériaux de Strasbourg (DCMI), 23 rue du Loess, 67034 Strasbourg, France.

Received date (to be automatically inserted after your manuscript is submitted)

Accepted date (to be automatically inserted after your manuscript is accepted)

\begin{abstract}
The synthesis of porphyrin dimers linked by metal ions is described and the X-ray structure of two new dimers is presented. As previously shown for diamagnetic metal ions, strong electronic interactions between the individual subunits were observed. Antiferromagnetic coupling between copper(II) porphyrins linked by palladium(II) or copper(II) ion was studied by EPR and SQUID measurements. For the palladium(II) linked dimer, the very small antiferromagnetic coupling was estimated by EPR measurements $\left(J<-1 \mathrm{~cm}^{-1}\right)$. For the trinuclear copper(II) linked dimer, a large antiferromagnetic coupling between the copper(II) ions was measured. In this trinuclear compound, the linking copper(II) ion is used as a relay to increase the interaction between the two copper(II)porphyrins.
\end{abstract}

KEYWORDS: Porphyrinoids, copper(II)porphyrin, porphyrin dimers, magnetic interactions, antiferromagnetic coupling.

*Correspondence to: Romain Ruppert, Institut de Chime, UMR 7177 du CNRS, Université de Strasbourg, 1 rue Blaise Pascal 67000 Strasbourg (France), e-mail : rruppert@unistra.fr. tel. : ++(33)368851700.

\section{INTRODUCTION}

Porphyrins are aromatic compounds with exceptional electronic properties widely found in Nature. Many synthetic modifications of their structure were conducted to improve mainly their electronic properties or catalytic activities. Porphyrins extended with conjugated systems were described in the literature and conjugated porphyrin arrays have been studied extensively [1]. Many of these studies were conducted to improve the electronic properties of the molecules, ie longer wavelength absorptions, better electron and/or energy transfer within the systems, etc. Despite the potential importance of molecular materials using magnetic interactions between metal ions [2], studies concerning the 
long-range magnetic interactions within long linear systems build from porphyrins are limited until now [3]. Cofacial porphyrinoid systems were in contrary studied very early [4] and these magnetic interactions are now quite well understood [5]. Coplanar di- or oligo-porphyrinoids were much less studied. Some typical dinuclear systems synthesized from porphyrinoids are represented in Figure 1. The interaction between two copper(II) ions located in fused phthalocyanines dimers was studied by several authors [6-9]. The groups of Barrett and Hoffman studied extensively the magnetic interactions between metal ions in homo- or hetero-dinuclear porphyrazines bearing an additional external ligand [10-13]. More recently, Matano and Imahori’s groups studied the magnetic coupling between two copper(II) in diazaporphyrin dimers [14-16]. Some studies of fused benzoporphyrin dimers, larger oligopyrrolic compounds or other porphyrinoids were also reported [17-21].

Figure 1. Examples of dinuclear molecules built from different porphyrinoids (all peripheral substituents ommitted).

The group of Osuka studied extensively covalently linked oligoporphyrins and especially triply fused molecules [22a]. For triply fused porphyrin dimers containing two copper(II) or two silver(II) ions (see Figure 2), they were able to show that long-range $\left(\mathrm{d}_{\mathrm{M}-\mathrm{M}}=8.42 \AA\right)$ antiferromagnetic couplings were present : $J=-2.86 \mathrm{~cm}^{-1}$ and $J=-7.28 \mathrm{~cm}^{-1}$ (the reported values in ref. $22 \mathrm{~b}$ were $J=-1.43 \mathrm{~cm}^{-1}$ and $-3.64 \mathrm{~cm}^{-1}$, see note in reference section) for the $\mathrm{Cu}-\mathrm{Cu}$ and the Ag-Ag dimers respectively [22b].

Figure 2. Bis-copper(II) or bis-silver(II) triply fused porphyrin dimers studied by Osuka and coll. [22b].

Porphyrins bearing enamino(thio)ketones were used as external ligands to bind metal ions. Numerous dimers linked by metal ions were prepared by our group (see Figure 3) [23]. Strong electronic interactions were present in these dimers [23c-23d]. For example, very fast energy transfers were observed between the two individual porphyrins of an unsymmetrical dimer. Magnetic interactions between metalloporphyrins were also found in porphyrin dimers linked by a simple amino group [24]. We here report on the synthesis and the magnetic properties of two copper(II)porphyrin dimers linked by a paramagnetic copper(II) ion or a diamagnetic palladium(II) ion (see Figure 3). These two dimers were also structurally characterized.

Figure 3. Chemical structures of the porphyrin dimers $\mathbf{C u}-\mathbf{C u}-\mathbf{C u}$ and $\mathbf{C u}-\mathbf{P d}-\mathbf{C u}$.

\section{RESULTS AND DISCUSSION}

\section{Synthesis and characterization}

The dimer Cu-Pd-Cu was described earlier and obtained by reaction of the monomeric copper(II)porphyrin $\mathbf{1}$ with $1 / 2$ equivalent of $\mathrm{Pd}(\mathrm{OAc})_{2}$ in toluene at $80{ }^{\circ} \mathrm{C}$ for 24 hours [23b]. The $\mathbf{C u}-\mathbf{C u}-\mathbf{C u}$ dimer was obtained in a similar manner, by reacting copper(II)porphyrin 1 with an excess of the appropriate starting source of copper(II) (see Scheme 1). The Cu-Cu-Cu dimer was isolated in very good yield (90\%) by using reaction conditions applied earlier for the palladium(II) linked dimer.

Scheme 1. Preparation of dimer $\mathrm{Cu}-\mathrm{Cu}-\mathrm{Cu}$. 
As expected and in good agreement with the data of diamagnetic dimers isolated before, the electronic spectra of the two dimers were bathochromically shifted when compared to monomer $\mathbf{1}$. In addition, and again as observed before for diamagnetic compounds [23b, 23d], this shift was dependant on the nature of the linking ion and was larger for the palladium(II) linked dimer. The electronic delocalization of the aromatic $\pi$-electrons of the two porphyrins is more efficient with participation of the $4 \mathrm{~d}$ orbitals of the linking $\mathrm{Pd}(\mathrm{II})$ than with the $3 \mathrm{~d}$ orbitals of the linking $\mathrm{Cu}(\mathrm{II})$. The larger bathochromic shift is not due to changes in the distances between the two copper(II)porphyrins as shown by comparing the values measured in two X-ray structures (vide infra). The lowest energy bands for the two dimers were located at $680 \mathrm{~nm}(\mathbf{C u}-\mathbf{C u}-\mathbf{C u})$ and $696 \mathrm{~nm}(\mathbf{C u}-\mathbf{P d}-\mathbf{C u})$ (see Figure 4).

Figure 4. Electronic spectra of the porphyrin dimers $\mathbf{C u}-\mathbf{C u}-\mathbf{C u}, \mathbf{C u}-\mathbf{P d}-\mathbf{C u}$, and of the copper(II)porphyrin monomer (dotted line).

The X-ray structures were solved for the two dimers $\mathbf{C u}-\mathbf{C u}-\mathbf{C u}$ (see Figure 5) and $\mathbf{C u}-\mathbf{P d}-\mathbf{C u}$ (see Figure 6). Selected representative bond lengths measured in the two structures are listed in Table 1. Both structures are centrosymmetric with the centers of symmetry located at the linking palladium(II) or copper(II) ions. Consequently, the three ions $\mathrm{Cu}-\mathrm{Pd}-\mathrm{Cu}$ and $\mathrm{Cu}-\mathrm{Cu}-\mathrm{Cu}$ are aligned in the two porphyrin dimers. In both structures, the coordination geometry around the linking ion was trans square planar. The copper(II)porphyrins were ruffled, becaue the presence of an additional fused aromtic ring introduced steric hindrance between the hydrogen atoms H2 and H24 (see Figure 5 and 6). The copper(II) ions in the core of the porphyrins were almost perfectly located in the plane of the four nitrogen atoms $\left(178^{\circ}<\right.$ angles $\left.\mathrm{N}-\mathrm{Cu}-\mathrm{N}<180^{\circ}\right)$. In both structures, the three methyl of one or several $t$-butyl groups are disordered between two positions.

Table 1. Selected bond lengths and distances measured in the X-ray structures of dimers $\mathbf{C u}-\mathbf{P d}-\mathbf{C u}$ and $\mathbf{C u}-\mathbf{C u}-\mathbf{C u}$.

Figure 5. X-ray structure of the porphyrin dimer $\mathbf{C u}-\mathbf{C u}-\mathbf{C u}$. Top : side view showing the planar linking complex and the ruffled structure of the copper(II)porphyrin (all meso-aryl groups omitted), bottom: view showing the centrosymmetric porphyrin dimer (all hydrogen atoms omitted).

The porphyrin dimer $\mathbf{C u}-\mathbf{C u}-\mathbf{C u}$ is centrosymmetric with the center located on the linking copper(II) ion. The four $\mathrm{Cu}-\mathrm{N}$ distances inside the core of the porphyrin are almost equal ( $\mathrm{d}=1.97-1.98 \AA$ ). The $\mathrm{Cu}-\mathrm{N}$ and $\mathrm{Cu}-\mathrm{O}$ distances around the linking ion are equal to $1.94 \AA$ and $1.96 \AA$ respectively. The coordination complex built from two enaminoketone ligands and the copper(II) ion is almost perfectly planar (see Figure 5, top view). The distance between the two external copper(II) is equal to $14.26 \AA$. The inter-plane angle between the $\mathrm{CuN}_{4}$ porphyrin plane and the $\mathrm{CuN}_{2} \mathrm{O}_{2}$ central square is approximatively $16^{\circ}$.

The porphyrin dimer $\mathbf{C u}-\mathbf{P d}-\mathbf{C u}$ is also centrosymmetric with the center located on the linking palladium(II) ion. The four $\mathrm{Cu}-\mathrm{N}$ distances inside the core of the porphyrin are almost equal ( $\mathrm{d}=1.97-1.98 \AA$ ). The Pd-N and Pd-O distances around the linking ion are equal to $1.98 \AA$ and $2.00 \AA$ respectively. The coordination complex built from two enaminoketone ligands and the palladium(II) ion is almost perfectly planar (see Figure 6, top view). The distance between the two external copper(II) is now a litle bit larger and is equal to $14.29 \AA$. The inter-plane angle between the $\mathrm{CuN}_{4}$ porphyrin plane and the $\mathrm{PdN}_{2} \mathrm{O}_{2}$ central square is approximatively $18^{\circ}$, and thus almost identical to the angle found in the structure of the $\mathbf{C u}-\mathbf{C u}-\mathbf{C u}$ dimer. The similarity of the two structures again demonstrated that the enhanced electronic communication was due to larger 4d-orbitals of the linking $\mathrm{Pd}(\mathrm{II})$ compared to the $\mathrm{Cu}(\mathrm{II}) 3 \mathrm{~d}$ - 
orbitals. A similar enhancement of the electronic communication was observed earlier by replacing $\mathrm{Pd}(\mathrm{II})$ by $\mathrm{Pt}(\mathrm{II})(4 \mathrm{~d}-$ orbitals vs 5d-orbitals) [23d-23e].

Figure 6. X-ray structure of the porphyrin dimer Cu-Pd-Cu. Top : side view showing the planar linking complex and the ruffled structure of the copper(II)porphyrin (all meso-aryl groups omitted), bottom: view showing the centrosymmetric porphyrin dimer (all hydrogen atoms omitted).

\section{Magnetic properties}

The static susceptibility measurement of dimer $\mathbf{C u}-\mathbf{P d}-\mathbf{C u}$ was performed in the 1.8-300 $\mathrm{K}$ temperature range with an applied field of 10000 Oe (See Figure 7 and Figure S9). The $\chi T v s . T$ curve is quasi constant in all the temperature range, with a Curie constant of $0.778 \mathrm{emu} \cdot \mathrm{K} \cdot \mathrm{mol}^{-1}$ in agreement with the presence of two non-coupled $\mathrm{Cu}$ (II) ions with a $g$ value of $2.04(2)$. Finally the $\mathrm{M}=\mathrm{f}(H)$ curve at $1.8 \mathrm{~K}$ fits relatively well with two Brillouin function for $S=1 / 2$ with $g$ $=2.08(2)($ see SI, Figure S10).

The static susceptibility measurement of dimer $\mathbf{C u}-\mathbf{C u}-\mathbf{C u}$ was performed in the 1.8-300 $\mathrm{K}$ temperature range with an applied field of 10000 Oe (see Figure 7). In dimer $\mathbf{C u}-\mathbf{P d}-\mathbf{C u}$ the two external $\mathrm{Cu}(\mathrm{II})$ were non-coupled. If the interaction between the two external $\mathrm{Cu}(\mathrm{II})$ ions is neglected in dimer $\mathbf{C u}-\mathbf{C u}-\mathbf{C u}$, the spin Hamiltonian is thus the following : $\mathbf{H}=-J \mathbf{S}_{\text {Cuint }} \cdot\left(\mathbf{S}_{\text {Cuext1 }}+\mathbf{S}_{\text {Cuext2 }}\right)+\beta\left[g_{\text {ext }}\left(\mathbf{S}_{\text {Cuext1 }}+\mathbf{S}_{\text {Cuext2 }}\right)+g_{\text {int }} \mathbf{S}_{\text {Cuint }}\right] \boldsymbol{H}$

If one considers only one $\mathrm{g}$ value for the two different copper(II) ions, the fit was clearly not perfect. By using two $g$ values for the two different copper(II) ions, the fit leads to the following values : $J=-25.2(5) \mathrm{cm}^{-1}, \mathrm{~g}=2.12(1)$ (for the central $\mathrm{Cu}(\mathrm{II})$ ), and $\mathrm{g}=2.09$ (1) (for the two peripheral $\mathrm{Cu}(\mathrm{II})$ ). Finally the $\mathrm{M}=\mathrm{f}(\mathrm{H})$ curve at $1.8 \mathrm{~K}$ fits well with a Brillouin function for $S=1 / 2$ (which correspond to the ground state of the system, see SI Figure $\mathrm{S} 12$ ).

This coupling constant value $\left(J=-25 \mathrm{~cm}^{-1}\right)$ found for this trinuclear porphyrin dimer is significantly larger than the values reported earlier for the fused $\mathrm{Cu}(\mathrm{II})$ porphyrin dimer of Osuka $\left(J=-2.86 \mathrm{~cm}^{-1}\right)$ [22b] and comparable with the value reported by Matano for a $\beta$ - $\beta$ linked $\mathrm{Cu}(\mathrm{II})$ azaporphyrin $\operatorname{dimer}\left(J=-19.3 \mathrm{~cm}^{-1}\right)$. The direct $\beta$ - $\beta$ linkage and the almost coplanar $\mathrm{Cu}(\mathrm{II})$ azaporphyrin dimers were invoked to explain the increase in the coupling values found in Matano's dimers [15].

Figure 7. $\chi T$ vs $T$ (green squares) and $\chi$ vs $T$ (red circles) for dimer $\mathbf{C u}-\mathbf{C u}-\mathbf{C u}$ and dimer $\mathbf{C u}-\mathbf{P d}-\mathbf{C u}$ (blue squares). Full lines correspond to the best fit considering two g values (see text).

\section{EPR studies}

The EPR spectra of frozen dilute solution of Cu-Pd-Cu complex $\left(10^{-4} \mathrm{M}\right)$ were recorded at X-band (Figure 8). From $4 \mathrm{~K}$ to $120 \mathrm{~K}$, the spectra display a pattern in the parallel region with a set of non-equidistant lines different from those of the monomeric $\mathrm{Cu}(\mathrm{II})$ porphyrin. This result is probably due to a low magnetic exchange interaction between the two copper(II) whereas the dipolar interaction is probably close to zero considering the distance between the two coppers (14.3 ̊). To simulate the spectrum (see figure S14 in SI), a spin hamiltonian (described in the SI) consisting of a sum of individual spin Hamiltonians for the isolated $\mathrm{Cu}(\mathrm{II})$ centers and an interacting Hamiltonian which accounts for the isotropic and anisotropic exchange interactions between the two $\mathrm{Cu}(\mathrm{II})$ centers was used.

Figure 8. X-Band EPR spectra of complex Cu-Pd-Cu (black) at $4 \mathrm{~K}$ and $\mathbf{C u}(\mathbf{I I})$ porphyrin (orange) at $28 \mathrm{~K}$ in frozen $\mathrm{CH}_{2} \mathrm{Cl}_{2}$ solution. 
The EPR spectra of the trinuclear complex $\mathbf{C u}-\mathbf{C u}-\mathbf{C u}$ were similarly recorded at X-band down to $4 \mathrm{~K}$ in frozen dilute solution in $\mathrm{CH}_{2} \mathrm{Cl}_{2}$ (see Table 2 for selected EPR data). The temperature dependent spectra are shown in figure 9. The spectrum below $c a$. $15 \mathrm{~K}$ was similar to a mononuclear copper complex. The spin hamiltonian parameters were close to those obtained for the monomeric copper(II)porphyrin (see Figure S15). Above $20 \mathrm{~K}$ two new features were observed as originating from the previous unresolved low temperature spectrum. The intensity of these two transitions increased up to $120 \mathrm{~K}$, whereas the intensity of the central line decreased continuously. The EPR spectrum at $22 \mathrm{~K}$ was different from the spectrum previously observed for $\mathbf{C u}-\mathbf{P d}-\mathbf{C u}$ with additional lines in the parallel component of the hyperfine tensor. The value of $\mathrm{A}_{\mathrm{z}}$ is divided by three compared to the mononuclear complex and a transition was also observed at half field. Further superhyperfine splitting was also observed at $67 \mathrm{~K}$ in the perpendicular part of the spectrum at $\sim 330 \mathrm{mT}$ due to the interaction of the unpaired electron with equivalent nitrogen nuclei of the porphyrin.

Table 2. EPR data for the three compounds in frozen $\mathrm{CH}_{2} \mathrm{Cl}_{2}$ solution.

Figure 9. X-band EPR spectra of $\mathbf{C u}-\mathbf{C u}-\mathbf{C u}$ in frozen $\mathrm{CH}_{2} \mathrm{Cl}_{2}$ solution at $4 \mathrm{~K}$ (in black) and $70 \mathrm{~K}$ (in purple).

Three exchange-coupled $S=1 / 2$ ions were expected to give two doublets $(S=1 / 2)$ and one quartet $(S=3 / 2)$ with the corresponding $\mathrm{S}_{\mathrm{Z}}$ spin projections $\mathrm{m}_{\mathrm{S}}= \pm 1 / 2$ and $\mathrm{m}_{\mathrm{S}}= \pm 1 / 2, \pm 3 / 2$. The distribution of the relative energies of these various spin states depends on the $J$ value. According to the SQUID measurements, the signal observed at $4 \mathrm{~K}$ is attributed to an $S=1 / 2$ spin and the ground state is a doublet (see figure $\mathrm{S} 15$ for the simulation). By increasing the temperature, a second doublet should be populated and then a quartet. The EPR lines observed above $20 \mathrm{~K}$ must be consequently ascribed to the thermal population of the $S=3 / 2$ spin multiplets with a small and unresolved zero-field splitting (see Figure S16 for the simulation). The EPR susceptibility obtained from the doubly integrated EPR line followed the same behavior than the static susceptibility (see Figure 10). It thus corroborated the magnetic behavior of this 3-spins system for the isolated molecule in dilute solution, being interpreted along the same way as a linear and symmetrical three $S=1 / 2$ spins model [25-26]. It confirmed the low spin ground state with $J=-19 \pm 0.5 \mathrm{~cm}^{-1}$. This is close to, although not identical to the value derived in the polycrystalline state. The difference in the $J$ value is better ascribed to different average molecular conformation in the frozen dilute solution compared to the solid state. As a matter of fact orbital overlap hence magnetic exchange is very sensitive to the molecular conformation. These results were in favor of the ability of $\mathrm{Cu}(\mathrm{II})$ to operate as a relay for magnetic exchange for the two copper porphyrins via probably a spin polarization mechanism along the two conjugated porphyrins.

Figure 10. Temperature dependence of the EPR intensity of $\mathbf{C u}-\mathbf{C u}-\mathbf{C u}$ in frozen $\mathrm{CH}_{2} \mathrm{Cl}_{2}$ solution.

\section{EXPERIMENTAL PART}

\section{General information}

The HRMS ESI and MALDI were obtained on a Bruker MicrOTOF. UV-vis spectra were recorded in dichloromethane with a Cary 5000 UV-Vis-NIR double-beam instrument. Chromatographic separations were performed with silica gel (Merck, 40-63 $\mu \mathrm{m}$ ). Dichloromethane was distilled over calcium hydride. All other solvents 
and reagents were used without further purification. The copper(II)porphyrin monomer and the palladium(II) linked dimer were prepared according to previously published procedures [23b].

Preparation of the dimer $\mathbf{C u}-\boldsymbol{C u}$ - $C u$. To a solution of the copper(II)-enaminoketoporphyrin (50 $\mathrm{mg}, 0.05 \mathrm{mmol}, 1 \mathrm{eq}$ ) in toluene $(20 \mathrm{~mL})$ was added $\mathrm{Cu}(\mathrm{OAc})_{2}(14 \mathrm{mg}, 0.08 \mathrm{mmol}, 1.5 \mathrm{eq})$. The mixture was refluxed for $18 \mathrm{~h}$ under argon. Evaporation of the solvent and cristallization from $\mathrm{CH}_{2} \mathrm{Cl}_{2} / n$-hexane/methanol afforded the title compound (49 $\mathrm{mg}, 0.02$ mmol, 90\%) as dark green crystals. Crystals suitable for X-ray diffraction analysis were obtained by vapor diffusion of methanol into a chlorobenzene solution. Maldi-TOF $(\mathrm{m} / \mathrm{z})$ : Calcd for $\mathrm{C}_{138} \mathrm{H}_{148} \mathrm{Cu}_{3} \mathrm{~N}_{10} \mathrm{O}_{2}\left(\mathrm{M}^{+} \bullet\right) 2165.967$; found

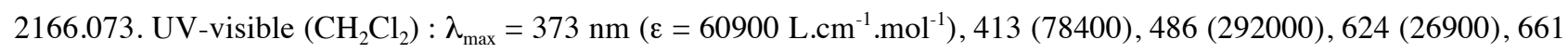
(42000), 680 (59200).

$\boldsymbol{X}$-Ray diffraction. The crystals were placed in oil, and a single crystal was selected, mounted on a glass fibre and placed in a low-temperature $\mathrm{N}_{2}$ stream. X-Ray diffraction data collection was carried out on a Bruker APEX II DUO Kappa-CCD diffractometer equipped with an Oxford Cryosystem liquid $\mathrm{N}_{2}$ device, using $\mathrm{Cu}-\mathrm{K} \alpha$ radiation $(\lambda=1.54178$ $\AA$ ) for compound $\mathbf{C u}-\mathbf{C u}-\mathbf{C u}$, and Mo-K $\alpha$ radiation $(\lambda=0.71073 \AA)$ for compound $\mathbf{C u}-\mathbf{P d}-\mathbf{C u}$. The crystal-detector distance was $40 \mathrm{~mm}$. The cell parameters were determined (APEX2 software) [27] from reflections taken from three sets of 20 frames, each at 10s exposure. The structures were solved by direct methods using the program SHELXS-2013 [28]. The refinement and all further calculations were carried out using SHELXL-2013 [29]. The H-atoms were included in calculated positions and treated as riding atoms using SHELXL default parameters. The non-H atoms were refined anisotropically, using weighted full-matrix least-squares on F2. A semi-empirical absorption correction was applied using SADABS in APEX2 [27]; transmission factors: $\mathrm{T}_{\min /} \mathrm{T}_{\max }=0.5863 / 0.7528$ for compound $\mathbf{C u}-\mathbf{C u}-\mathbf{C u}$ and $\mathrm{T}_{\min /} \mathrm{T}_{\max }=0.6539 / 0.7456$ for compound Cu-Pd-Cu. The SQUEEZE instruction in PLATON [30] was applied. The residual electron density was assigned to two chlorobenzene molecules for compound $\mathbf{C u}-\mathbf{C u}-\mathbf{C u}$, and to two molecules of the 1,2-dichlorobenzene solvent for compound $\mathbf{C u}-\mathbf{P d}-\mathbf{C u}$.

Crystal data $\mathbf{C u}-\mathbf{C u}-\mathbf{C u} . \mathrm{C}_{138} \mathrm{H}_{148} \mathrm{Cu}_{3} \mathrm{~N}_{10} \mathrm{O}_{2}, \mathrm{M}=2169.28$ g.mol ${ }^{-1}$, green plate, crystal size 0.35 x 0.25 x $0.11 \mathrm{~mm}$, triclinic, space group P-1, $a=9.3827(2) \AA, b=15.4981(4) \AA, c=24.8388(7) \AA, \alpha=73.993(2)^{\circ}, \beta=81.347(2)^{\circ}, \gamma=$ $86.276(2)^{\circ}, \mathrm{V}=3431.30(15) \AA^{3}, \mathrm{Z}=1, \rho_{\text {calc }}=1.050 \mathrm{Mg} / \mathrm{m}^{3}, \mathrm{~T}=173(2) \mathrm{K}, \mathrm{Cu}-\mathrm{K} \alpha=1.54178,1.868<\theta<66.892$, 42895 reflections measured, 11993 unique reflections, $\mathrm{R}_{1}=0.0984, \mathrm{wR}_{2}=0.1552, \mathrm{GoF}=1.028 . \mathrm{CCDC} \mathrm{Nr} 1920312$.

Crystal data $\mathrm{Cu}-\mathrm{Pd}-\mathrm{Cu} . \mathrm{C}_{150} \mathrm{H}_{156} \mathrm{Cl}_{4} \mathrm{Cu}_{2} \mathrm{~N}_{10} \mathrm{O}_{2} \mathrm{Pd}, \mathrm{M}=2506.12$ g.mol ${ }^{-1}$, black prism, crystal size $0.40 \times 0.18 \times 0.12$ $\mathrm{mm}$, triclinic, space group P-1, $a=15.6352(9) \AA, b=16.9970(11) \AA, c=20.0876(12) \AA, \alpha=105.830(2)^{\circ}, \beta=$ $106.0470(10)^{\circ}, \gamma=93.3380(10)^{\circ}, \mathrm{V}=4883.9(5) \AA^{3}, \mathrm{Z}=1, \rho_{\text {calc }}=0.852 \mathrm{Mg} / \mathrm{m}^{3}, \mathrm{~T}=173(2) \mathrm{K}, \mathrm{MoK} \alpha=0.71073,1.403$ $<\theta<28.032$, transmission factors: $\mathrm{T}_{\min } / \mathrm{T}_{\max }=0.6539 / 0.7456,87752$ reflections measured, 23526 unique reflections, $\mathrm{R}_{1}$ $=0.1012, \mathrm{wR}_{2}=0.1883, \mathrm{GoF}=1.023 . \mathrm{CCDC} \mathrm{Nr} 1920313$.

Magnetic measurements. Magnetic measurements were performed at the Institut de Physique et Chimie des Matériaux de Strasbourg (UMR CNRS-UdS 7504) using a Quantum Design SQUID-VSM magnetometer. Data were corrected for the sample holder and diamagnetism was estimated from Pascal constants.

Dimer Cu-Cu-Cu : M = 2169.36 g/mol, $\mathrm{m}=4.56 \mathrm{mg}$, shape correction = 1.064

Dimer Cu-Pd-Cu : M = 2212.23 g/mol, $\mathrm{m}=5.23 \mathrm{mg}$, shape correction $=1.035$

EPR measurements. EPR spectra were recorded on an EMXplus spectrometer (Bruker Biospin GmbH), equipped with a high sensitivity resonator (4119HS-W1, Bruker) operating at X-band (ca. 9.4 GHz). An ESR900 cryostat (Oxford Instruments) was used for the low temperature measurements. Sample solutions in quartz tubes were sealed after being degassed by three freeze-pump-thaw cycles. Simulations of EPR spectra were achieved by means of lab-made scripts based on Easyspin toolbox under Matlab (Mathworks (C) environment [26]. Accurate simulations for $\mathbf{C u}-\mathbf{P d - C u}$ and 
$\mathbf{C u}-\mathbf{C u}-\mathbf{C u}$ were prevented by the large spectral line widths and $g$ strain was used to adjust the fits. The temperature dependence intensity of the double integrated EPR signal $(c)$ for the $\mathbf{C u}-\mathbf{C u}-\mathbf{C u}$ complex was fitted by the the equation used for the magnetic measurements.

\section{CONCLUSION}

The synthesis of two porphyrin dimers linked by copper(II) or palladium(II) was described. Both compounds were structurally characterized. Strong electronic interactions between the porphyrins were found for both dimers. This was clearly shown by the large bathochromic shifts of the Q bands and the splitting of the Soret bands in the electronic spectra of the dimers. Magnetic interactions between the copper(II) ions were also observed within these two dimers. Whereas the magnetic coupling between the two copper(II) ion was negligible for the $\mathbf{C u}-\mathbf{P d}-\mathbf{C u}$ dimer, the antiferromagnetic coupling between the copper(II) ions was quite large $\left(J=-25.2 \mathrm{~cm}^{-1}\right)$ for the $\mathbf{C u}-\mathbf{C u}-\mathbf{C u} \operatorname{dimer}$. The linking copper(II) can be described as a relay to increase the interactions between the two copper(II)porphyrins. In the near future, by building larger copper(II) linked oligoporphyrins, long-range magnetic coupling can be envisaged. The introduction of different paramagnetic ions as linking units to generate heteronuclear dimers might even lead to completely different coupling values between the paramagnetic sites. This was shown earlier by the groups of Hoffman and Barrett in the case of heterobinuclear porphyrazines [10-13].

\section{ACKNOWLEDGEMENTS}

Continuous financial support from the University of Strasbourg and the CNRS are acknowledged. MAC thanks the FRC-Labex CSC for her PhD fellowship (ANR-10-LABX-0026 CSC). HD thanks the French Ministry of Research for a PhD fellowship. We are grateful to the French EPR Federation of Research (RENARD, IR-RPE CNRS 3443). DBL is grateful to NSERC of Canada for generous research support.

\section{REFERENCES}

1. Tanaka T and Osuka A. Chem. Soc. Rev. 2015; 44: 943-969.

2. Kahn O. in Molecular Magnetism, VCH: New York, 1993.

3. Segawa H, Machida D, Senshu Y, Nakazaki, Hirakawa K and Wu F. Chem. Commun. 2002; 3032-3033.

4. Eaton SS, Eaton GR and Chang CK. J. Am. Chem. Soc. 1985; 107: 3177-3184.

5. Kobayashi N. Coord. Chem. Rev. 2002; 227: 129-152.

6. a) Leznoff CC, Lam H, Marcuccio SM, Nevin WA, Janda P, Kobayashi N and Lever ABP. J. Chem. Soc., Chem. Commun. 1987; 699-701. b) Wang K, Huang C, Pan H, Kobayashi N and Jiang J. Inorg. Chem. Front. 2017; 4: 110-113.

7. a) Lelièvre D, Bosio L, Simon J, André JJ and Bensebaa F. J. Am. Chem. Soc. 1992; 114: 4475-4479. b) Lelievre D, Damette O and Simon J. J. Chem. Soc., Chem. Commun. 1993; 939-940.

8. Handa M, Kataoka N, Ito Y, Tonomura T, Hiromitsu I, Sugimori T, Sogabe K and Kasuga K. Bull. Chem. Soc. Jpn. 2004; 77: 1647-1648.

9. Ikeue T, Sawada N, Matsumoto N, Miyazaki A, Sugimori T, Koikawa M, Hiromisu I, Yoshino K, Mikuriya M, Kataoka Y and Handa M. J. Porphyrins Phthalocyanines 2014; 18: 1-7.

10. Zhao M, Stern C, Barrett AGM and Hoffman BM. Angew. Chem. Int. Ed. 2003; 42: 462-465.

11. Zhao M, Zhong C, Stern C, Barrett AGM and Hoffman BM. Inorg. Chem. 2004; 43: 3377-3385. 
12. Zhao M, Zhong C, Stern C, Barrett AGM and Hoffman BM. J. Am. Chem. Soc. 2005; 127: 9769-9775.

13. Zhong C, Zhao M, Goslinski T, Stern C, Barrett AGM and Hoffman BM. Inorg. Chem. 2006; 45: $3983-3989$.

14. Omomo S, Maruyama Y, Furukawa K, Furuyama T, Nakano H, Kobayashi N and Matano Y. Chem. Eur. J. 2015; 21: $2003-2010$.

15. Matano Y, Fujii D, Shibano T, Furukawa K, Higashino T, Nakano H and Imahori H. Chem. Eur. J. 2014; 20: 3342-3349.

16. Kawamata M, Sugai T, Minoura M, Maruyama Y, Furukawa K, Holstrom C, Nemykin VN, Nakano H and Matano Y. Chem. Asian J. 2017; 12: 816-821.

17. See for example : a) Chmielewski PJ. Angew. Chem. Int. Ed. 2010; 49: 1359-1361. b) Toganoh M, Furuta H. Chem. Commun. 2012; 48: 937-954.

18. Kobayashi N, Numao N, Kondo R, Nakajima S and Osa T. Inorg. Chem. 1991; 30: 2241-2244.

19. Yamazumi K, Nishimura K, Hisamune Y, Nagae Y, Uchiyama T, Kamitani K, Hirai T, Nishibori M, Mori S, Karasawa S, Kato T, Kurukawa K, Ishida M and Furuta H. Chem. Eur. J. 2017; 23: 15322-15326.

20. Ooi S, Tanaka T, Ikeue T, Yamasumi K, Ueta K, Shimizu D, Ishida M, Furuta H and Osuka A. Chem. Asian J. 2019; 14: 1771-1776.

21. Mitsuno K, Yoshino T, Gupta I, Mori S, Karasawa S, Ishida M and Furuta H. Angew. Chem. Int. Ed. 2017; 56: $14252-14256$.

22. a) Tsuda A and Osuka A. Science, 2001; 293: 79-82. b) Ikeue T, Furukawa K, Hata H, Aratani N, Shinokubo H, Kato T and Osuka A. Angew. Chem. Int. Ed. 2005; 44: 6899-6901. Note : the spin hamiltonian used in reference $22 \mathrm{~b}$ is different from the one used in this study. Therefore to compare the different coupling constant values, the reported values were multiplied by 2 .

23. a) Richeter S, Jeandon C, Ruppert R and Callot HJ. Chem. Commun. 2001; 91-92. b) Richeter S, Jeandon C, Gisselbrecht JP, Ruppert R and Callot HJ. J. Am. Chem. Soc. 2002; 124: 6168-6179. c) Abdelhameed M, Langlois A, Karsenti PL, Richeter S, Ruppert R and Harvey PD. Chem. Commun. 2014; 50: 14609-14612. d) Dekkiche H, Buisson A, Langlois A, Karsenti PL, Ruhlmann L, Ruppert R and Harvey P. Chem. Eur. J. 2016; 22: 1048410493. e) Dekkiche H, Buisson A, Langlois A, Karsenti PL, Ruhlmann L, Harvey PD and Ruppert R. Inorg. Chem. 2016; 55: 10329-10336. f) Carvalho MA, Dekkiche H, Karmazin L, Sanchez F, Vincent B, Kanesato M, Kikkawa Y and Ruppert R. Inorg. Chem. 2017; 56: 15081-15090.

24. Merahi K, Pereira AMVM, Jeandon C, Ruhlmann L, Cavaleiro JAS, Neves MGPMS, Orio M, Turek P, Choua S and Ruppert R. J. Porphyrins Phthalocyanines 2016; 20: 1233-1243.

25. a) Tanaka M, Matsuda K, Itoh T and Iwamura H. J. Am. Chem. Soc. 1998; 120: 7168-7173. b) Maspoch D, RuizMolina D, Wurst K, Vidal-Gancedo J, Rovira C and Veciano J. Dalton Trans. 2004; 1073-1082.

26. Stoll S and Schweiger A. J. Magn. Reson. 2006; 178: 42-55.

27. “M86-E01078 APEX2 User Manual”, Bruker AXS Inc., Madison, USA, 2006.

28. Sheldrick GM. Acta Cryst. 1990; A46: 467-473.

29. Sheldrick GM. Acta Cryst. 2008; A64: 112-122.

30. Spek AL. J. Appl. Cryst. 2003; 36: 7-13. 
Table 1. Selected bond lengths and distances measured in the X-ray structures of dimers $\mathbf{C u}-\mathbf{P d}-\mathbf{C u}$ and $\mathbf{C u}-\mathbf{C u}-\mathbf{C u}$.

\begin{tabular}{|c|c|c|c|}
\hline $\mathrm{Cu}-\mathrm{Pd}-\mathrm{Cu}$ & distance $(\AA)$ & $\mathrm{Cu}-\mathrm{Cu}-\mathrm{Cu}$ & Distance $(\AA)$ \\
\hline $\mathrm{Cu} 1-\mathrm{N} 1$ & $1.980(2)$ & Cu1-N1 & $1.979(3)$ \\
\hline $\mathrm{Cu} 1-\mathrm{N} 2$ & $1.978(2)$ & $\mathrm{Cu} 1-\mathrm{N} 2$ & $1.983(3)$ \\
\hline $\mathrm{Cu} 1-\mathrm{N} 3$ & $1.975(2)$ & $\mathrm{Cu} 1-\mathrm{N} 3$ & $1.974(3)$ \\
\hline $\mathrm{Cu} 1-\mathrm{N} 4$ & $1.983(2)$ & Cu1-N4 & $1.979(3)$ \\
\hline $\mathrm{H} 2-\mathrm{H} 24$ & 2.128 & $\mathrm{H} 2-\mathrm{H} 24$ & 2.167 \\
\hline Pd1-N5 & $1.982(2)$ & $\mathrm{Cu} 2-\mathrm{N} 5$ & $1.936(3)$ \\
\hline Pd1-O1 & $2.0012(17)$ & $\mathrm{Cu} 2-\mathrm{O} 1$ & $1.964(2)$ \\
\hline $\mathrm{Cu} 1-\mathrm{Pd} 1$ & $7.1435(5)$ & $\mathrm{Cu} 1-\mathrm{Cu} 2$ & $7.1289(5)$ \\
\hline $\mathrm{Cu} 1-\mathrm{Cu} 1^{\prime}$ & $14.2869(9)$ & Cu1-Cu1' & $14.2577(10)$ \\
\hline
\end{tabular}


Table 2. EPR data for the three compounds in frozen $\mathrm{CH}_{2} \mathrm{Cl}_{2}$ solution.

\begin{tabular}{|c|cccccc|}
\hline Compound & $g_{/ /}$ & $g_{+}$ & $\begin{array}{c}\mathrm{A}_{/ /}{ }^{63} \mathrm{Cu} \\
(\mathrm{MHz})\end{array}$ & $\begin{array}{c}\mathrm{A}_{+}{ }^{63} \mathrm{Cu} \\
(\mathrm{MHz})\end{array}$ & $\begin{array}{c}\mathrm{A}^{14} \mathrm{~N} \\
(\mathrm{MHz})\end{array}$ & $\mathrm{D}(\mathrm{MHz})$ \\
\hline $\mathbf{C u}(\mathbf{I I})$ porphyrin ${ }^{\mathbf{1}}$ & 2.223 & 2.065 & 540 & 30 & 50 & - \\
$\mathbf{C u}-\mathbf{C u}-\mathbf{C u}(\mathbf{4 K}), \mathbf{S}=\mathbf{1 / 2}$ & 2.252 & 2.049 & 540 & 30 & - & 40 \\
$\mathbf{C u}-\mathbf{C u}-\mathbf{C u}(\mathbf{7 0 K}), \mathbf{S}=\mathbf{3 / 2}$ & 2.262 & 2.045 & 180 & 10 & 450 \\
\hline
\end{tabular}

${ }^{1}$ See Figure S13 for the simulated spectrum. 

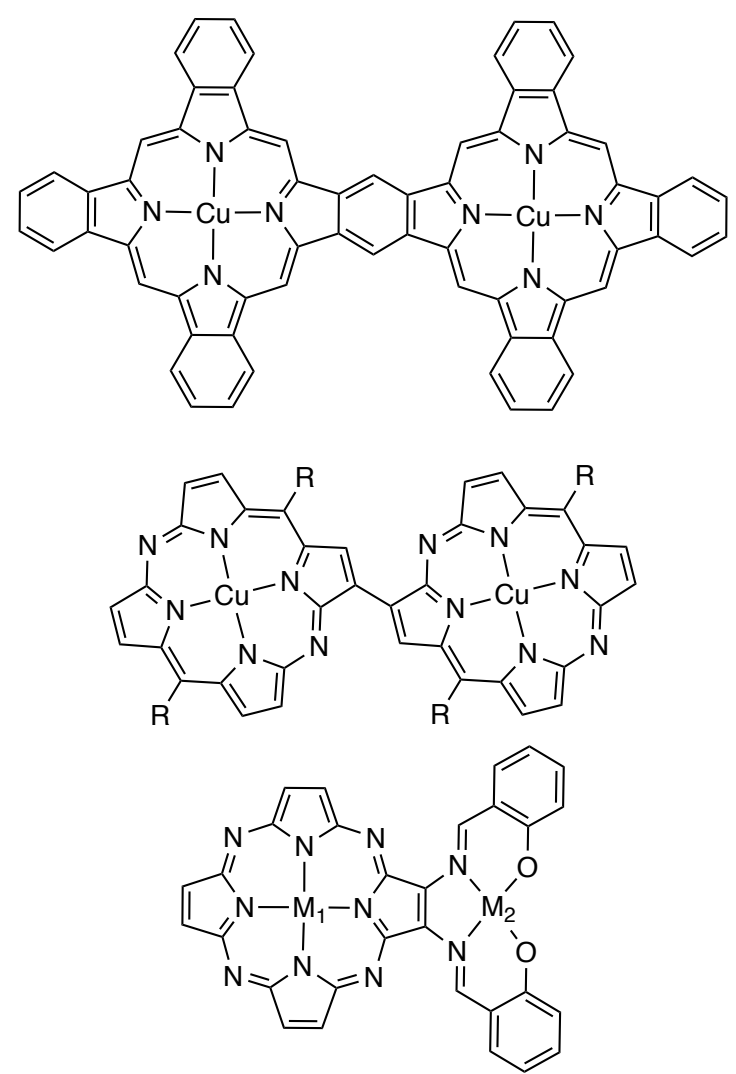

$\mathrm{M}_{1}$ and/or $\mathrm{M}_{2}=\mathrm{Cu}$ and/or $\mathrm{V}=\mathrm{O}$

Figure 1. Examples of dinuclear molecules built from different porphyrinoids (all peripheral substituents ommitted). 


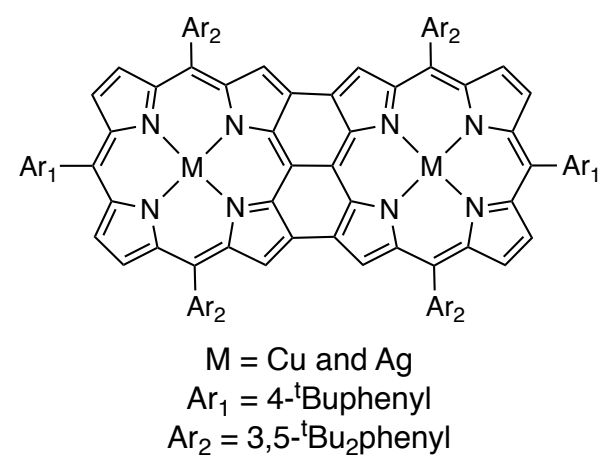

Figure 2. Bis-copper(II) or bis-silver(II) triply fused porphyrin dimers studied by Osuka and coll. [22b]. 


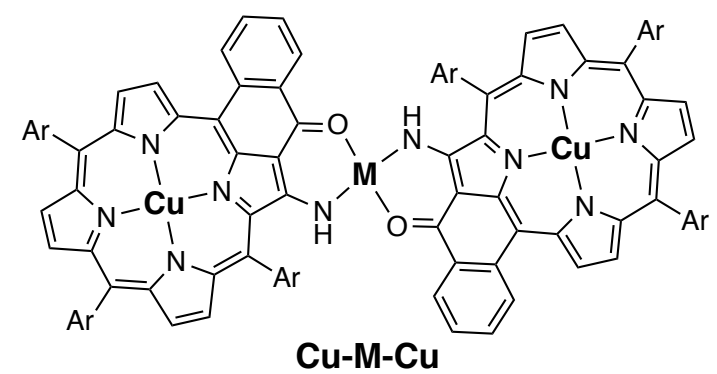

$\mathrm{M}=\mathrm{Cu}$ and $\mathrm{Pd}$

$\mathrm{Ar}=3,5-{ }^{\mathrm{t}} \mathrm{Bu} \mathrm{p}_{2}$ phenyl

Figure 3. Chemical structures of the porphyrin dimers $\mathbf{C u}-\mathbf{C u}-\mathbf{C u}$ and $\mathbf{C u}-\mathbf{P d}-\mathbf{C u}$. 


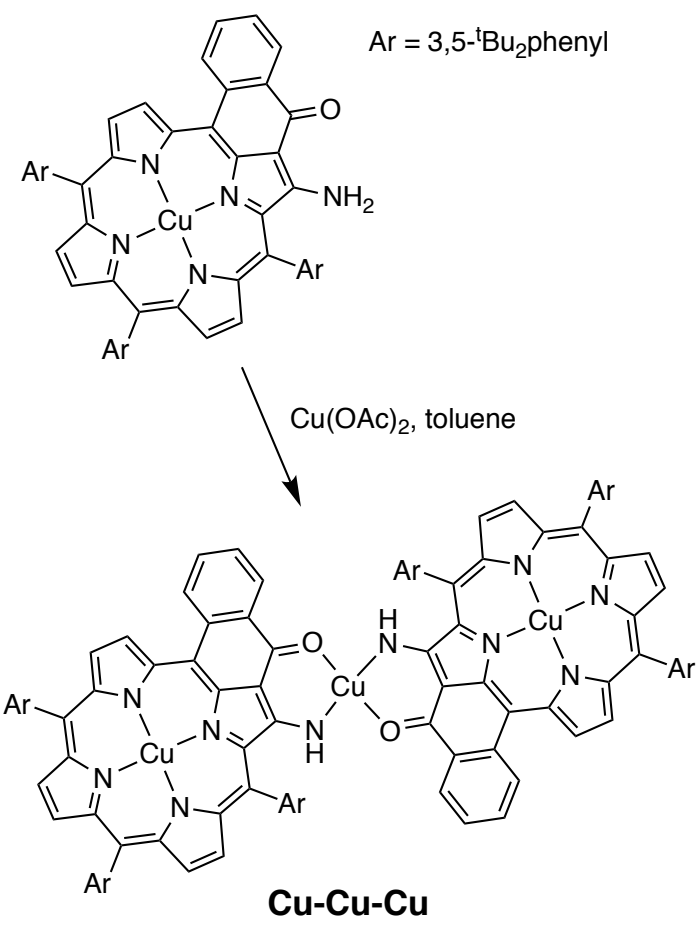

Scheme 1. Preparation of dimer $\mathbf{C u}-\mathbf{C u}-\mathbf{C u}$. 


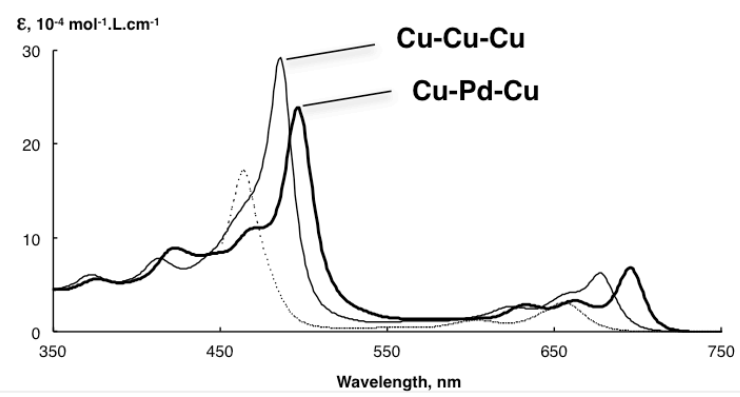

Figure 4. Electronic spectra of the porphyrin dimers $\mathbf{C u}-\mathbf{C u}-\mathbf{C u}, \mathbf{C u}-\mathbf{P d}-\mathbf{C u}$, and of the copper(II)porphyrin monomer (dotted line). 

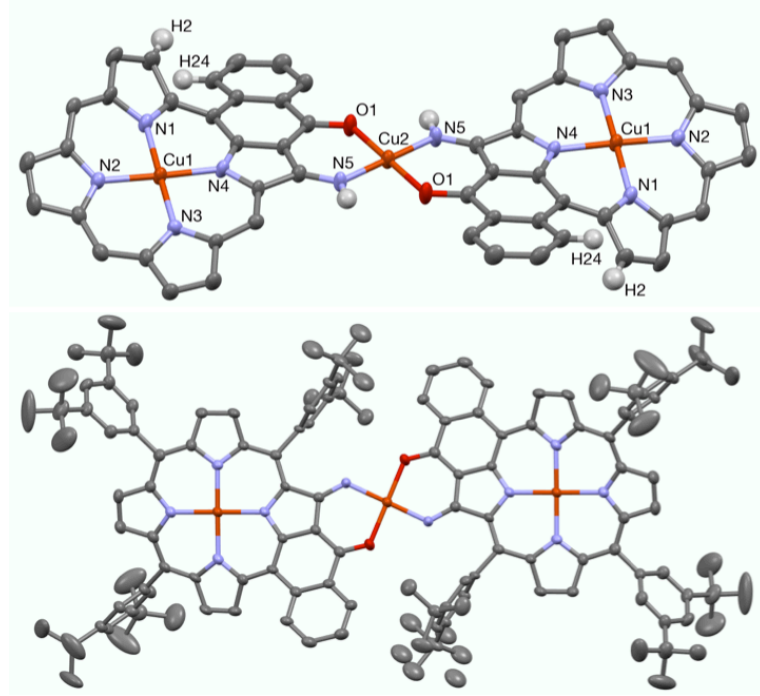

Figure 5. X-ray structure of the porphyrin dimer $\mathbf{C u}-\mathbf{C u}-\mathbf{C u}$. Top : side view showing the planar linking complex and the ruffled structure of the copper(II)porphyrin (all meso-aryl groups omitted), bottom: view showing the centrosymmetric porphyrin dimer (all hydrogen atoms omitted). 

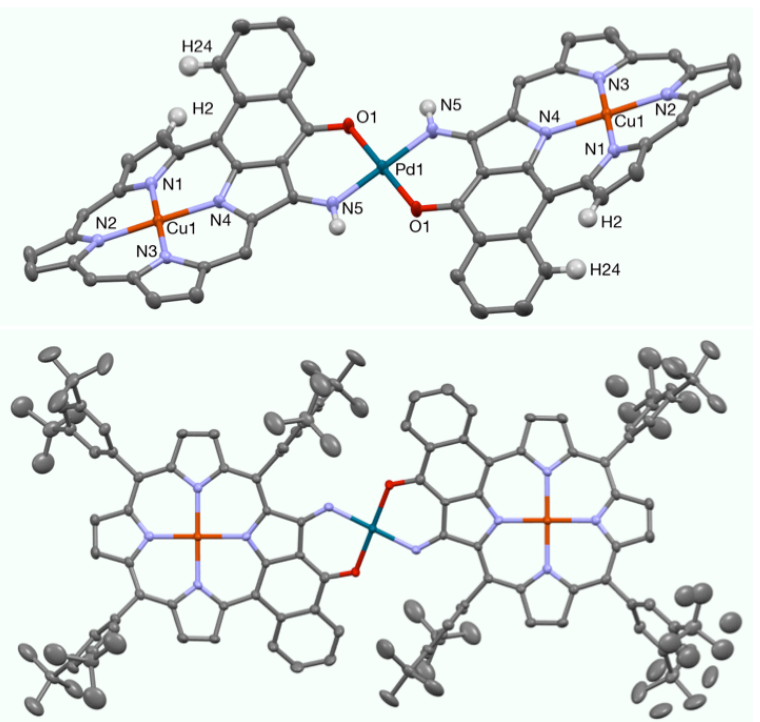

Figure 6. X-ray structure of the porphyrin dimer Cu-Pd-Cu. Top : side view showing the planar linking complex and the ruffled structure of the copper(II)porphyrin (all meso-aryl groups omitted), bottom: view showing the centrosymmetric porphyrin dimer (all hydrogen atoms omitted). 


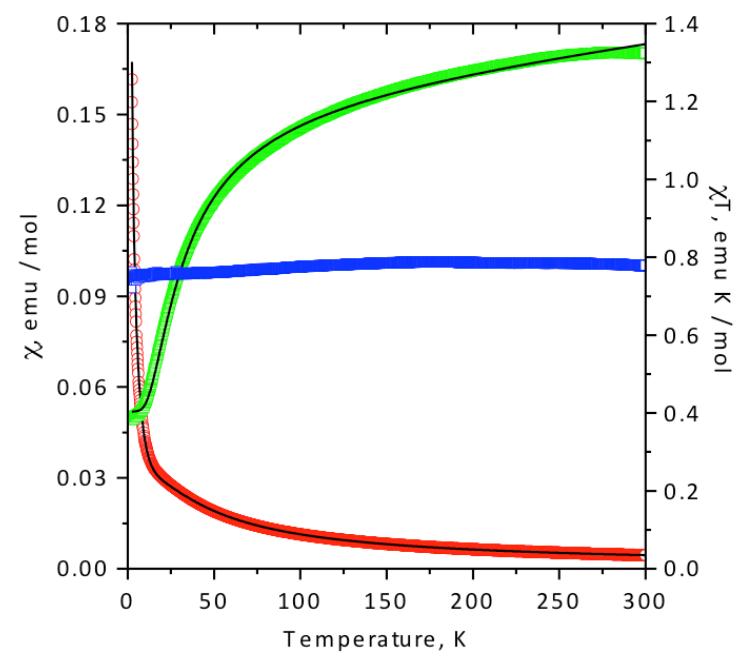

Figure 7. $\chi T$ vs $T$ (green squares) and $\chi$ vs $T$ (red circles) for dimer $\mathbf{C u}-\mathbf{C u}-\mathbf{C u}$ and dimer $\mathbf{C u}-\mathbf{P d}-\mathbf{C u}$ (blue squares). Full lines correspond to the best fit considering two g values (see text). 


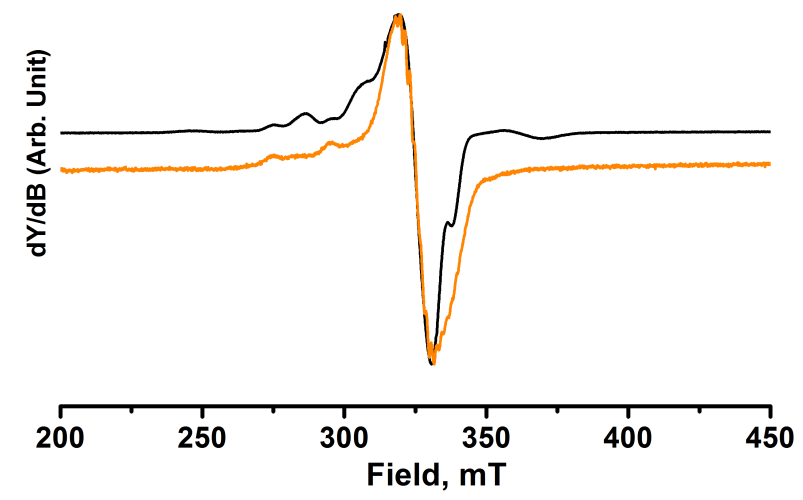

Figure 8. X-Band EPR spectra of complex $\mathbf{C u}-\mathbf{P d}-\mathbf{C u}$ (black) at $4 \mathrm{~K}$ and $\mathbf{C u}(\mathbf{I I})$ porphyrin (orange) at $28 \mathrm{~K}$ in frozen $\mathrm{CH}_{2} \mathrm{Cl}_{2}$ solution. 


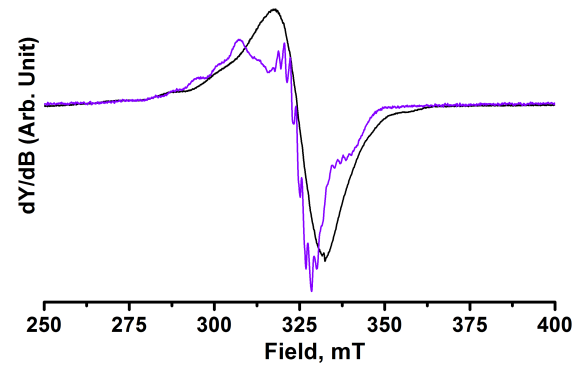

Figure 9. X-band EPR spectra of $\mathbf{C u}-\mathbf{C u}-\mathbf{C u}$ in frozen $\mathrm{CH}_{2} \mathrm{Cl}_{2}$ solution at $4 \mathrm{~K}$ (in black) and $70 \mathrm{~K}$ (in purple). 


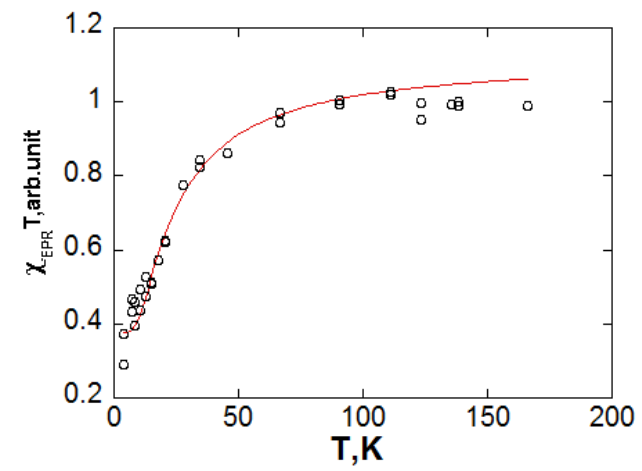

Figure 10. Temperature dependence of the EPR intensity of $\mathbf{C u}-\mathbf{C u}-\mathbf{C u}$ in frozen $\mathrm{CH}_{2} \mathrm{Cl}_{2}$ solution. 